\title{
The epidemiology of childhood brain injury in the state of Selangor and Federal Territory of Kuala Lumpur, Malaysia
}

\author{
Ee Lin Tay ${ }^{1}$, Shaun Wen Huey Lee ${ }^{2}$, Sabariah Faizah Jamaluddin ${ }^{3}$ Cai Lian Tam and Chee Piau Wong ${ }^{1 *}$
}

\begin{abstract}
Background: There are limited studies describing the epidemiology of childhood brain injury, especially in developing countries. This study analyses data from the Malaysian National Trauma Database (NTrD) registry to estimate the incidence of childhood brain injury among various demographic groups within the state of Selangor and Federal Territory of Kuala Lumpur.

Methods: This study analysed all traumatic brain injury cases for children ages 0-19 included in the 2010 NTrD report.

Results: A total of 5,836 paediatric patients were admitted to emergency departments (ED) of reporting hospitals for trauma. Of these, 742 patients (12.7\%) suffered from brain injuries. Among those with brain injuries, the mortality rate was 11.9 and $71.2 \%$ were aged between 15 and 19. Traffic accidents were the most common mode of injury (95.4\%). Out of the total for traffic accidents, $80.2 \%$ of brain injuries were incurred in motorcycle accidents. Severity of injury was higher among males and patients who were transferred or referred to the reporting centres from other clinics. Glasgow Coma Scale (GCS) total score and type of admission were found to be statistically significant, $X^{2}(5, N=178)=66.53, p<0.001$, in predicting patient outcomes. According to this analysis, the overall rate of childhood brain injury for this one year period was 32 per 100,000 children while the incidence of significant (moderate to severe) brain injury was approximately 8 per 100,000 children.

Conclusions: This study provides an overview of traumatic brain injury rates among children within the most populous region of Malaysia. Most brain injuries occurred among older male children, with traffic, specifically motorcycle-related, accidents being the main mode of injury. These findings point to risk factors that could be targeted for future injury prevention programs.
\end{abstract}

Keywords: Traumatic brain injury, Incidence, Road traffic accident, Children

\section{Background}

Traumatic brain injury (TBI) is a major public health concern which contributes significantly to mortality and morbidity among youth [1, 2]. Previously published studies conducted in other countries such as in the United States, Australia and New Zealand have estimated the rate of childhood brain injury to range from 75 to 1,373 per 100,000 among children aged below 15 years old [3-6]. It is difficult, however, to accurately assess true incidence rates

\footnotetext{
* Correspondence: wong.chee.piau@monash.edu

'Tan Sri Jeffrey Cheah School of Medicine and Health Sciences, Monash

University Malaysia Campus, Petaling Jaya, Malaysia

Full list of author information is available at the end of the article
}

as these studies varied according to case ascertainment and inclusion criteria. For example, the two population based studies $[4,5]$ included cases presented to emergency departments (ED), hospital admissions and deaths. By contrast, the highest rate reported (1,373 per 100,000 children) [6] resulted from a longitudinal study of a single birth cohort, and included ED cases, hospital admissions and deaths, as well as cases presented to general practitioners (GP).

Data on incidence of TBI in South East Asian Nations (ASEAN) and other developing countries are not readily available. In Malaysia, a hospital-based study by Rohana and colleagues [7] estimated that $4.75 \%$ of all paediatric 
cases admitted to the emergency department were related to TBI. This study was conducted more than a decade ago and, to the authors' knowledge, there are no other published studies elating to childhood brain injury in Malaysia.

In this report the authors analysed the NTrD data on childhood brain injury in Malaysia in 2010. Specifically, the authors analysed in detail the incidence of childhood brain injury in the states of Selangor and Federal Territory of Kuala Lumpur, which fall within the same geographical region of Peninsular Malaysia, and together comprise about $20 \%$ of the total population of the country [8].

\section{Method}

\section{Data source}

This was a cross-sectional, retrospective study analysing data from the National Trauma Database (NTrD). This database recorded information related to trauma patients in Malaysia from 2006 to 2010. Thirteen hospitals from various states in Malaysia participated as reporting centres for the registry. All tertiary referral hospitals $(N=6)$ operated by the Ministry of Health within the states of Selangor and Kuala Lumpur were reporting centres for this registry, and data from all $(N=6)$ these reporting centres was retrieved for analysis. Two tertiary academic hospitals within this region did not participate. A standardised form was used to collect data from each hospital [9]. Information collected included: a) patient's demographic and clinical characteristics, b) admission details, c) injury related details such as mode and mechanism of injury, place of injury, and injury intent, d) diagnosis and operative procedures, as well as, e) patient outcomes. The Malaysian Institute of Road Safety Research (MIROS) oversaw data collection within participating hospitals for 2010. The MIROS database included all cases relating to road traffic accidents (RTA) while NTrD recorded major trauma cases. This ensured a comprehensive and fairly complete data collection, hence the data for 2010 was used for this analysis. Trauma patients aged between 0 and 19 years old and patients with head or brain injuries were included in the analysis.

\section{Measures}

The NTrD contains several trauma scales which were used to classify the severity of patients' injury. These include the Glasgow Coma Scale (GCS) score that measures one's consciousness level [10], ranging from 3 to 15 , with score of $13-15,9$ to 12 and 3 to 8 indicating mild, moderate and severe injury respectively. The other scale used was the Injury Severity Score (ISS) [11] which is an overall injury score derived from the Abbreviated Injury Scale (AIS). ISS scores range from 0 to 75 , with higher scores indicating more severe injuries. GCS and ISS scores were assessed and documented by emergency department (ED) physicians on ED admission. Patients' outcomes (alive or dead), discharge disposition and length of stay (LOS) were used as key predictors of morbidity and mortality.

\section{Statistical analyses}

The age up to 19 was used to define the paediatric population in this analysis to align with the Malaysia intercensal population estimates denominator data [8] to facilitate calculation. Independent $\mathrm{t}$-tests were performed to compare the severity of brain injuries (GCS) between gender, types of admission and for patients whom did or did not wear protective gear, especially helmets. Logistic regression was used to assess various prognostic factors on patient outcomes (alive or dead). IBM SPSS (version 20) was used for statistical analysis.

\section{Results}

\section{Epidemiological data}

From January 1, 2010 to December 31, 2010, a total of 5,836 patients aged 0-19 years old were admitted to ED of the six reporting hospitals with trauma. Of all trauma patients, $12.7 \%$ (742) presented with brain injuries. Of brain injury patients, 75.1, 4.4 and $20.5 \%$ had mild, moderate and severe brain injuries respectively. The median age of these patients was 17 (range from 0 to 19 years old). Males were 4 times more likely than females to suffer from TBI across all age groups. The highest rate of TBI admissions was observed in adolescent aged between 15 and 19 years old, who comprised $72.0 \%(N=534)$ of total admissions (Table 1).

About three quarters of the cases recorded $(n=551$, $74.1 \%)$ were direct admissions to the reporting hospitals while $191(25.7 \%)$ cases were referrals or transfers from other hospitals. The median duration of admission was 1 day (1 to 160 days) with an overall total of 3,200 hospital bed days accrued by the 742 patients. Seventy seven $(n=77,10.4 \%)$ patients were admitted to the intensive care unit (ICU). These patients spent a median of 4 days ( 1 to 105 days) and a total of 568 bed days in the ICU. Most of these patients were alive at discharge, $11.9 \%(n=88)$ of the patients died (Table 1$)$. The mode of brain injuries is illustrated in Table 2 . The most frequent mode of injury was RTA, which accounted for almost 95.4 \% of all injuries recorded.

\section{Injury variables}

RTA occurred more frequently among patients aged 10 years and above $(n=654,92.4 \%)$ while falling as mode of injury was more frequent among children below 9 years old ( $n=18,85.7 \%$; Fig. 1). RTA involved mainly motorcycle accidents $(n=595,80.2 \%)$. Data on the use of helmet among RTA survivors with TBI was available in 441 patients, who were either cyclists or motorcycle riders. Helmets were worn in $67.3 \%(n=297)$ of cases, while $32.7 \%(n=144)$ of riders were not wearing helmets 
Table 1 Baseline demographic and clinical characteristics of the study cohort $(N=742)$

\begin{tabular}{lll}
\hline Variable & & Number (\%) \\
\hline Gender & Male & $594(80.0)$ \\
Nationality & Malaysian & $148(20.0)$ \\
& Non-Malaysian & $722(97.3)$ \\
Age (years) & $0-4$ & $20(2.7)$ \\
& $5-9$ & $45(6.1)$ \\
& $10-14$ & $30(4.0)$ \\
GCS & $15-19$ & $133(17.9)$ \\
& Mild (13-15) & $534(72.0)$ \\
ISS, Mean (SD) & Moderate (9-12) & $557(75.1)$ \\
Type of admission & Severe (3-8) & $33(4.4)$ \\
& & $152(20.5)$ \\
Outcome & Direct admission & $6.74(8.36)$ \\
& Transferred/ referred & $551(74.3)$ \\
& Alive & $191(25.7)$ \\
\hline a missing values & Death & $652(88.1)$ \\
\hline
\end{tabular}

${ }^{\mathrm{a}} 2$ missing values

GCS Glasgow coma scale, ISS Injury severity score

at the time of the accidents. The use of helmets was found to reduce the severity level (GCS) of injuries (Mean $=14.35$, $S D=2.357)$ in comparison to those who did not wear helmets $(M=13.51, S D=3.547)$, t $(408)=2.876, p=0.004$.

There were significant differences in injury severity based on gender and type of admission. Higher severity was observed in males based on GCS $(M=12.30, S D=4.536)$ compared to females $(M=13.59, S D=3.610), t(738)=$ $-3.203, p=0.001)$. Patients who were transferred or referred to the reporting centres $(M=10.99, S D=4.971)$ had more severe brain / head injuries than patients who were admitted directly $(M=13.11, S D=4.039), t$ $(738)=5.860, p<0.001$ (Table 3 ). GCS scores also correlated negatively with the length of hospital stay (LOS) $(r=-0.369 ; p<0.001)$ but not length of ICU stay $(r=-0.083 ; p>0.05)$. As expected, patients with higher GCS scores had lower ISS scores $(r=-0.556 ; p<0.001)$.

Table 2 Mode of brain injury

\begin{tabular}{lllllll}
\hline Mode of injury & \multicolumn{7}{l}{ Age Group } \\
\cline { 2 - 7 } & $0-4$ & $5-9$ & $10-14$ & $15-19$ & Total & Percentage (\%) \\
\hline Road traffic accident & 27 & 27 & 132 & 522 & 708 & 95.4 \\
Falls & 15 & 3 & 1 & 2 & 21 & 2.8 \\
Industrial accident & 0 & 0 & 0 & 3 & 3 & 0.4 \\
Others & 1 & 0 & 0 & 6 & 7 & 1.0 \\
Unknown & 2 & 0 & 0 & 1 & 3 & 0.4 \\
Total & 45 & 30 & 133 & 534 & 742 & 100.0 \\
\hline
\end{tabular}

\section{Predictors of survival}

This analysis used a logistic regression model containing five independent variables (gender, age, type of admission, GCS total score, and total ISS) to predict survival. The original model containing all five factors was statistically significant, $X^{2}(5, n=178)=66.53, p<0.001$, in predicting patient outcomes. However, as shown in Table 4, when accounting for the inter-relationships among the predictors, only two factors remain statistically significant (GCS total and type of admission). The strongest predictor of patient outcome was type of admission, with odds ratio (OR) of 5.63 (95\% CI 2.61 to 12.15), whereby patients who were admitted directly were much more likely to survive. Patients with higher GCS scores were more likely to survive (OR 1.53, $95 \%$ CI 1.30 to 1.79 ).

\section{Incidence}

The estimated population aged 19 years old and below was 2,274 678 in the 2010 population census [8]. Consequently, the calculated incidence of childhood brain injury based on the 2010 NTrD was approximately 32 per 100,000 children. Moderate to severe brain injury (significant), which usually leads to death or significant sequelae was approximately 8 per 100,000 children.

\section{Discussion}

This analysis provides an insight into the epidemiology of childhood brain injuries in Malaysia. Brain injury was found to be much more frequent among children from 15 to 19 years old (72\%) as well as among males $(80 \%)$. The most common mode of injury was road traffic accidents (RTA, $95.4 \%$ ). More specifically, motorcycle accidents accounted for about $80 \%$ of traffic accident-related TBI. This study provides the first comprehensive overview of childhood brain injury within the most populous region of Malaysia in the last 5 years. The standardized form of data collection across participating hospitals strengthened the reliability and accuracy of the data analysed.

Male patients were more likely than females to have been injured in RTA across all age groups.

Males in this study were 4 times more likely to suffer from TBI than their female counterparts and the vast majority of them were RTA victims. This trend is similar that seen in most previous studies where the ratio of male to female TBI tends to be around $2: 1[3,4,7,12,13]$. This is likely to be due to higher risk-taking behaviour among males [14]. This is similar to a previous study which shows that Malaysian male drivers are three times more likely than female drivers to be involved in RTA [15].

In the current study, RTA was, by far, the leading mode of brain injury, accounting for almost $95.4 \%$ of all cases reported, out of which over half were adolescents aged between 17 and 19 years. However, this should be interpret with caution as the data could have skewed toward RTA as 


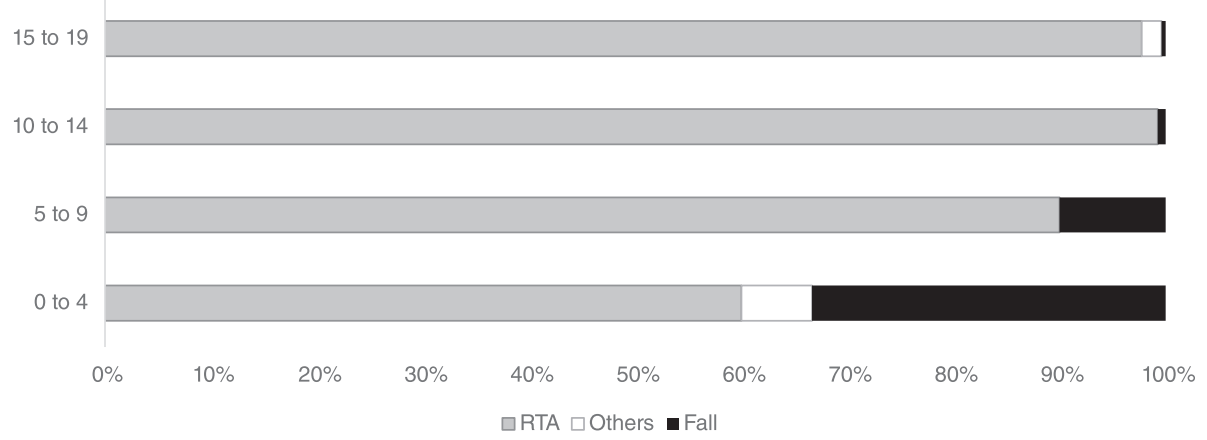

Fig. 1 An inverse trend of distribution of road traffic accident (RTA) and fall as mode of injury according to age is shown. The percentage of RTA was higher among children aged 10 years and above while the percentage of fall was higher among children below 9 years old

the main cause given the involvement of MIROS throughout the data collection period. Nevertheless, this is still consistent with a previous study [16] showing that Malaysia has the highest rate of RTA fatalities among ASEAN countries. More than half of these fatalities are motorcyclists aged 16 to 20 years old [16]. Pedestrians, motorcyclists and cyclists are the usual casualties in RTA [17]. Such numbers clearly point to a need for improving traffic safety in Malaysia.

Falls were the most common mode of traumatic brain injury among children aged 9 and below. However, the rate of falls was lower (18 out of 75 cases, $24 \%$ ) in comparison to Rohana's [7] study which reported $63 \%$ of fall related injuries. Although the cause of falls was not recorded in the $\mathrm{NTrD}$, lack of adult supervision was reported as the main cause of accidents by Rohana. This decline may be attributed to the enforcements of various child maltreatment (neglect and abuse) prevention programmes [18], the enforcement of Child Act 2001 [19] and increased awareness among the public.

Our results are similar to previous studies that have indicated a bimodal age-related distribution of TBI: We observed an initial peak among younger children below 4 years old and another among older children over 15 years

Table 3 Summary of variables and difference in injury severity

\begin{tabular}{lll}
\hline Variable & Mean (SD) & Injury Severity (GCS) \\
\hline Gender & & \\
- Male & $12.30(4.536)$ & \\
$\quad$ - Female & $13.59(3.610)$ & $P=0.001$ \\
Type of admission & & \\
$\quad$ - Transferred/ Referred & $10.99(4.971)$ & \\
- Direct & $13.11(4.039)$ & $P<0.001$ \\
Use of helmet & & \\
- Yes & $13.58(3.631)$ & \\
- No & $13.07(4.003)$ & $P>0.05$ \\
\hline
\end{tabular}

old $[4,6,20-22]$. These changes appear to relate to the mode of injuries as previously eluded.

The overall incidence of childhood brain injuries in this analysis was 32 per 100,000 children with the incidence of significant childhood brain injuries at 8 per 100,000 children. These results are much lower than other studies. For example, childhood brain injury ranges have been estimated at 280 per 100,000 children in United Kingdom and 842 per 100,000 children in the United States [3, 4]. These rates, however, cannot be compared directly due to different methodologies and inclusion criteria. Nevertheless, the incidence of significant brain injuries in our analysis was fairly similar to that conducted by B Mitra, P Cameron and W Butt [5] in Australia. Using similar inclusion criteria, they reported a TBI rate of 7 per 100,000 children per year. These vastly different results support Roozenbeek's [17] call for greater standardization in epidemiological monitoring of TBI. The incidence found from this analysis should be a good approximation of the actual incidence. This is because most brain injuries in Malaysia usually present to hospitals ED and rarely treated by the general practitioners or at home. Whilst mild brain injuries may be seen in private hospitals, moderate to severe injuries are usually referred to (by private hospitals) the public hospitals in $\mathrm{MOH}$, especially patients who have no insurance cover.

Table 4 Logistic regression predicting the patients' outcomes

\begin{tabular}{llllllllll}
\hline & B & S.E. & Wald & df & $p$-value & Odds ratio & \multicolumn{2}{l}{ 95 Cl } \\
\hline Gender & .999 & .584 & 2.924 & 1 & .087 & 2.715 & .864 & 8.528 \\
Age & .005 & .042 & .013 & 1 & .910 & 1.005 & .926 & 1.090 \\
GCS & .422 & .080 & 27.511 & 1 & .000 & 1.525 & 1.302 & 1.785 \\
Adm & 1.727 & .393 & 19.338 & 1 & .000 & 5.626 & 2.605 & 12.149 \\
ISS & -.018 & .018 & 1.022 & 1 & .312 & .982 & .949 & 1.017 \\
\hline GCS, GCS total score; Adm, types of admission; ISS, total ISS. Cox and Snell \\
$\mathrm{R}^{2}=0.312$. Nagelkerke R ${ }^{2}=0.417$. Correct classification = 79.8 \%
\end{tabular}


In this study, patients who were admitted directly to the reporting hospitals were 5 times more likely to survive than those who were transferred or referred from other hospitals or clinics. This is likely to be due to the fact that, most severe cases were usually brought to the reporting hospitals directly (which are tertiary hospital with appropriate expertise to care for these patients). The increase in mortality in the referred cases could also be due to the delay in managing these cases caused by the transfers. Primary admissions to reporting hospitals are more likely to include patients with milder injury and a much wider range of injuries. There other many possible contributing factors to this finding such as the adequacy of care of the primary hospital or the transport system. This is beyond the scope of this current analysis. Nevertheless, this result suggests that a more comprehensive evaluation of mortality rates across health care providers may be warranted. Such a project should include detailed evaluations of local trauma care and referral systems [5], as well as methods of regionalizing trauma care to ensure that patients promptly receive appropriate medical care [23]. Such regionalization could also improve organizational efficiency and allocation of resources to ensure better health care delivery.

There are several limitations in this study. As this research was retrospective in nature, the data evaluated may have included selection biases. The collaboration with MIROS in 2010 might have caused the data to skew towards RTA as the main mode of brain injury. The National Trauma Database (NTrD) registry only collected data from tertiary hospitals overseen by the Ministry of Health. Data from academic centres and private hospitals was not included in this registry. Consequently, the rates found in this analysis are an underestimation of the actual incidence of TBI. Nevertheless, as previous studies indicate that $70 \%$ of TBI present to public hospitals [24], we can assume that the data used in this study represent approximately $70 \%$ of total TBI cases in this region of Malaysia.

\section{Conclusions}

To the authors' knowledge, there has been no published research on the epidemiology of childhood brain injury in Malaysia for the past 17 years. Thus, this study provides an important update in this area. The incidence of childhood brain injury was 32 per 100,000 children. In general, our findings indicate that the incidence of childhood brain injury in Malaysia follows similar patterns to that seen in other countries. The findings regarding the incidence rates of significant childhood brain injury are similar to other studies that used similar methodology and inclusion criteria. The study also reinforced the need to continue the traffic safety awareness initiatives and programmes especially among motorcyclists. In addition standardized data recording as well as more extensive post-discharge follow-up and data collection will be useful to understanding patients' recovery processes and enable the optimal provision of rehabilitation services.

\section{Ethics approval and consent to participate}

Ethics approval was obtained from the National Medical Research and Ethics Committee (MREC) for the NTrD registry (NMRR 05-01-158). Public notice as a form of consent was approved by the MREC for all participants of the registry. These opt-out notices were placed at various treatment and waiting areas in the reporting centres. Permission was obtained from the registry committee to analyse the data for this study. Ethics exemption from Monash University Human Research Ethics Committee (MUHREC) has also been obtained (CF14/1869 - 2014000962).

\section{Availability of data and materials}

The authors do not have the permission from NTrD registry to republish the raw data. In order to access the data, kindly request permission from the registry via this link (http://www.acrm.org.my/ntrd/).

\section{Abbreviations}

AIS: abbreviated injury scale; ED: emergency department; GCS: glasgow coma scale; ICU: intensive care unit; ISS: injury severity score; LOS: length of hospital stay; MIROS: Malaysian institute of road safety research; NTrD: national trauma database; OR: odds ratio; RTA: road traffic accident; TBI: traumatic brain injury.

\section{Competing interests}

The authors declare that they have no competing interests.

\section{Authors' contributions}

TEL conceived of the study and drafted the manuscript. SWHL and TCL participated in the design of the study, statistical analysis and write up. SFJ provided insights to the discussion and write up. WCP conceived and participated in the design of the study and overall coordination and helped to draft the manuscript. All authors read and approved the final manuscript.

\section{Authors' information}

ELT has a Bachelor of Science in Psychology (Honours) degree from Sunway University, Malaysia. This degree is accredited by Lancaster University in the UK. ELT is currently pursuing her PhD in Monash University Malaysia, working on a research related to virtual rehabilitation for children with neurological disability.

SWHL is a senior lecturer in School of Pharmacy, Monash University Malaysia. SWHL completed his undergraduate studies in University of Strathclyde via a twinning programme with the International Medical University. He then continued to pursue his PhD from 2003 to 2006. SWHL has a broad research interest ranging from metabolic to urological diseases.

SFJ is the Senior Consultant and Head of Department of Emergency and Trauma in Sungai Buloh Hospital, Malaysia. She obtained her M.B.B.Ch from the University of Alexandria Egypt and diploma in Immediate Medical Care from Royal College of Surgeons, Edinburgh and Master of Medicine in Anaesthesiology from University Kebangsaan Malaysia (UKM). SFJ is the chairman of the steering committee of the National Trauma Database (NTrD).

$T C L$ is a senior lecturer in Jeffrey Cheah School of Medicine \& Health Sciences, Monash University Malaysia. She is a counselling psychologist, obtaining her Doctoral of Counselling Psychology from the National University of Malaysia (UKM) in 2005. TCL is a registered counsellor with special interest in the variety of challenges facing adolescents in modern Malaysia. She is actively involved in writing commentaries on current issues for a local daily newspaper and monthly magazine.

CPW is a paediatrician and Child Neurologist. He receives his basic medical training in University of Malaya and his post graduate paediatric training in UK with the Royal College of Paediatrics and Child Health (RCPCH) and his 
doctoral research with Newcastle University. CPW is currently attached to Monash University Malaysia. He is a fellow of RCPCH and a member of British Paediatric Neurology Association, Malaysian Paediatric Association (MPA), Malaysian Society of Neuroscience (MSN), Asian Oceania Child Neurology Association (AOCNA), member of the Academy of Science Malaysia and a member of the Malaysian Qualification Agency. CPW has conducted a population based study into the epidemiology and outcome of childhood non traumatic coma in the North of England.

\section{Acknowledgements}

The authors would like to thank the Director General of Health for giving the permission to publish and also thank the National Trauma Database Registry for granting the permission to access the database (NMRR-05-01-158). We would also like to further thanks Dr Gregory Bonn of Nagoya University for his help in proofreading this manuscript.

\section{Author details}

${ }^{1}$ Tan Sri Jeffrey Cheah School of Medicine and Health Sciences, Monash University Malaysia Campus, Petaling Jaya, Malaysia. ${ }^{2}$ School of Pharmacy, Monash University Malaysia Campus, Petaling Jaya, Malaysia. ${ }^{3}$ Emergency and Trauma Department, Sungai Buloh Hospital, Petaling Jaya, Malaysia.

Received: 10 February 2015 Accepted: 19 April 2016

Published online: 27 April 2016

\section{References}

1. Hoofien D, Gilboa A, Vakil E, Donovick PJ. Traumatic brain injury (TBI) 10-20 years later: a comprehensive outcome study of psychiatric symptomatology, cognitive abilities and psychosocial functioning. Brain Inj. 2001;15(3):189-209.

2. Zaloshnja E, Miller T, Langlois JA, Selassie AW. Prevalence of long-term disability from traumatic brain injury in the civilian population of the United States, 2005. J Head Trauma Rehabil. 2008;23(6):394-400.

3. Faul M, Xu L, Wald MM, Coronado VG. Traumatic Brain Injury in the United States: Emergency departments visits, hospitalizations and deaths 2002-2006. In Centers for Disease Control and Prevention 2010. http://www.cdc.gov/ traumaticbraininjury/pdf/blue_book.pdf. Accessed 24 May 2014

4. Hawley CA, Ward AB, Long J, Owen DW, Magnay AR. Prevalence of traumatic brain injury amongst children admitted to hospital in one health district: a population-based study. Injury. 2003;34(4):256-60.

5. Mitra B, Cameron P, Butt W. Population-based study of paediatric head injury. J Paediatr Child Health. 2007;43(3):154-9.

6. McKinlay A, Grace RC, Horwood L, Fergusson DM, Ridder EM, MacFarlane MR. Prevalence of traumatic brain injury among children, adolescents and young adults: Prospective evidence from a birth cohort. Brain Inj. 2008;22(2):175-81.

7. Rohana J, Ong LC, Abu HA. Epidemiology of head injury in Malaysian children: a hospital-based study. Med J Malaysia. 1998;53(3):217-22.

8. Intercensal mid-year population estimates 2001-2009. Department of Statistics, Putrajaya. 2014. https://newss.statistics.gov.my/newss-portalx/ep/ epDownloadContentSearch.seam?cid=15173. Accessed 21 June 2014.

9. National Trauma Database. https://newss.statistics.gov.my/newssportalx/ep/ epDownloadContentSearch.seam?cid=15173 (2012). Accessed 20 May 2014.

10. Teasdale G, Jennett B. Assessment of coma and impaired consciousness. A practical scale. Lancet. 1974;2(7872):81-4.

11. Baker PS, O'neill BB, Haddon BW, Long BW. The injury severity score: a method for describing patients with multiple injuries and evaluating emergency care. J Trauma. 1974;14(3):187-96.

12. Kraus JF, Black MA, Hessol N, Ley P, Rokaw W, Sullivan C, Bowers S, Knowlton S, Marshall L. The incidence of acute brain injury and serious impairment in a defined population. Am J Epidemiol. 1984;119(2):186-201.

13. Assiry K, Abdulmutali $H$, Alqahtani A, Alyahya A, Elawad M. Traumatic Head Injuries in Children: Experience from Asir, KSA. Online J Med Med Sci Res. 2014;3(5):44-7.

14. Corrigan JD, Selassie AW, Orman JA. The epidemiology of traumatic brain injury. J Head Trauma Rehabil. 2010;25(2):72-80.

15. Nurul Huda J, Ho JS, Jamilah MM. A survey of risk of accidents in Malaysia. In: REAAA Conference Kuala Lumpur Convention Centre, Malaysia; 2013.

16. Muhammad Marizwan AM, Varhelyi A. Motorcycle fatalities in Malaysia. IATSS Research. 2012;36:30-9.

17. Roozenbeek B, Maas Al, Menon DK. Changing patterns in the epidemiology of traumatic brain injury. Nat Rev Neurol. 2013;9(4):231-6.
18. Cheah IGS, Choo WY. Child maltreatment prevention readiness assessment in Malaysia. In: Country Report. World Health Organization. 2011. http:// www.who.int/violence_injury_prevention/violence/child/malaysia_rap_cm. pdf. Aceessed 18 July 2014.

19. The Commissioner of Law revision. Child Act 2001. In: Laws of Malaysia. Authority of the Revision of Laws Act in 1968. 2006. http://www.agc.gov. my/agcportal/uploads/files/Publications/LOM/EN/Act\%20611.pdf. Accessed 18 July 2014.

20. Crowe L, Babl F, Anderson V, Catroppa C. The epidemiology of paediatric head injuries: data from a referral centre in Victoria. Australia J Paediatr Child Health. 2009;45(6):346-50.

21. Rutland-Brown W, Langlois JA, Thomas KE, Xi YL. Incidence of traumatic brain injury in the United States, 2003. J Head Trauma Rehabil. 2006;21(6):544-8.

22. Schneier AJ, Shields BJ, Hostetler SG, Xiang H, Smith GA. Incidence of pediatric traumatic brain injury and associated hospital resource utilization in the United States. Pediatrics. 2006;118(2):483-92.

23. Martinez R, Carr B. Creating integrated networks of emergency care: from vision to value. Health Aff (Project Hope). 2013;32(12):2082-90.

24. Lim TO, Sivasampu S, Ariza Z, Nabilah M. Chapter 1: Overview on hospitals and specialists services in Malaysia. In: Naitonal Healthcare Establishments \& Workforce Statistics 2008-2009. 2011. http://www.crc.gov.my/nhsi/wp-content/ uploads/publications/NHEWS_Hospitals_Report/chapter1.pdf. Accessed 28 October 2015

\section{Submit your next manuscript to BioMed Central and we will help you at every step:}

- We accept pre-submission inquiries

- Our selector tool helps you to find the most relevant journal

- We provide round the clock customer support

- Convenient online submission

- Thorough peer review

- Inclusion in PubMed and all major indexing services

- Maximum visibility for your research

Submit your manuscript at www.biomedcentral.com/submit
Biomed Central 